\title{
COMBINATION OF INFORMATION CODING METHODS AS A CONDITION OF EFFECTIVE PHYSICAL CONCEPTS DEVELOPMENT IN PRIMARY SCHOOL
}

(C) 2019

Samoilov Evgeny Andreevich, doctor of pedagogical sciences, professor of Physics, Mathematics and Methods of Teaching Department

Samara State University of Social Sciences and Education (Samara, Russian Federation)

Abstract. The paper discusses a way to resolve the contradiction between high requirements of the modern Federal state educational standard (FSES) to the level of training and intellectual development of primary school graduates and the lack of effective didactic means and teaching methods that ensure assimilation of students abstract elements of the curriculum, which were previously studied only in high school. The researches by Russian psychologists (V.N. Druzhinin, M.A. Holodnaya, etc.) show that an essential element of the individual intellect are mental conceptual structures, and their optimal development is provided by a collection of specially prepared learning tasks, involving the use of three modalities of experience (sensual-effective, figurative, symbolic). On the example of teaching methods design of electromagnetic induction in primary school, the author shows the sequence and specifics of the teacher's actions, which allow to build a complex of didactic means for the full enrichment of the mental experience of students and organize their educational activities in accordance with the needs of school physical education, taking into account psychological laws of individual intelligence development together with modern private didactic approaches to the management of intellectual development of students. The proposed method of training and a set of training tasks that meet the requirements of the target orientation, target sufficiency, increasing the level of difficulty, motivational orientation, were approved in Samara Aviation Lyceum № 135 and showed high efficiency in terms of intellectual development and training of primary school students.

Keywords: individual intellect; teaching physics in primary school; control of intellectual development of students; methods of information coding; mental conceptual structures; physical concepts development; set of educational tasks; complex of educational tasks; study of electromagnetic induction in primary school.

\section{ТРУДОВОЕ ВОСПИТАНИЕ И ПРОФЕССИОНАЛЬНАЯ ОРИЕНТАЦИЯ В БИОЛОГИЧЕСКОМ И ЭКОЛОГИЧЕСКОМ ОБРАЗОВАНИИ ШКОЛЬНИКОВ}

(C) 2019

Семенов Александр Алексеевич, кандидат биологических наук, доцент, заведующий кафедрой биологии, экологии и методики обучения

Самарский государственный сочиально-педагогический университет (2. Самара, Российская Федераиия)

Аннотащия. Отношение человека к труду, активность его трудовой деятельности, творческий подход к ней зависит от верного выбора профессии, и в частности - специальности. В связи с этим правильная подготовка учащихся к будущей трудовой деятельности имеет первостепенное значение в воспитании школьников. Одной из основ трудового воспитания является профориентация учащихся. Она рассматривается как условие всестороннего и гармоничного развития личности; осуществляется в единстве обучения биологии и экологии с основными направлениями духовно-нравственного развития, воспитания и социализации учащихся. Профессиональная ориентация предполагает целенаправленную деятельность по формированию у школьников внутренней потребности и готовности к сознательному выбору профессии и состоит из нескольких компонентов: профессиональное просвещение; профессиональное воспитание; профессиональная консультация; профессиональная адаптация. Профессиональное просвещение вооружает школьников знаниями о профессиях в области биологии и экологии, условиях их выбора, воспитывает у них положительное отношение к труду, формирует профессиональные предпочтения. Под профессиональным воспитанием понимают воспитание у учащихся профессионально важных качеств личности: коммуникабельности, профессионального долга и чести, ответственности, профессиональной этики. Учитель знакомит учащихся с профессиями, связанными с биологией и экологией; изучает и развивает интересы, склонности и способности каждого ученика; включает профориентационную тематику в оформление учебного кабинета; обеспечивает регулярную демонстрацию видеофильмов, отражающих применение достижений биологической науки в производстве. Профессиональная консультация призвана оказать необходимую помощь учащимся в профессиональном самоопределении. Она предполагает информирование школьников о биологических и экологических профессиях. Профессиональная адаптация связана с овладением учащимися необходимыми для будущей профессии знаниями и практическими умениями. Существует прямая зависимость между уровнем предметных знаний и умений и скоростью приспособления человека к профессиональному обучению и трудовой деятельности. Таким образом, трудовое воспитание и профессиональная ориентация учащихся в процессе обучения биологии и экологии представляют собой целостную систему, состоящую из взаимосвязанных и дополняющих друг друга компонентов, объединённых общностью цели и единством управления. 
Ключевые слова: воспитание; обучение; духовно-нравственное развитие; труд; профессия; профессиональная ориентация; биология; экология; учащиеся; школа; трудовое воспитание; методика обучения биологии; методика обучения экологии; биологическое образование; экологическое образование; среднее общее образование.

Современные экономические реалии, нестабильность рынка труда, появление новых профессий и специальностей породили новые требования к трудовому воспитанию и профессиональной подготовке личности. Для каждого человека важно правильно подобрать соответствующую ему профессию. Становление личности происходит с малых лет, следовательно, трудовое воспитание и профессиональная подготовка подрастающего поколения должны осуществляться со школьной скамьи.

Вопросам трудового воспитания посвящены работы известных отечественных и зарубежных педагогов: В.Г. Белинского, А.И. Герцена, Н.К. Крупской, А.В. Луначарского, А.С. Макаренко, Р. Оуэна, И. Песталоцци, Ж.-Ж. Руссо, В.А. Сухомлинского, К.Д. Ушинского, Н.Г. Чернышевского, С.Т. Шацкого и др.

По определению К.Д. Ушинского, трудовое воспитание - это целенаправленный процесс, в ходе которого у школьников формируется готовность трудиться, стремление и умение реально участвовать в построении общества, вырабатывается положительное отношение к труду [1].

В.А. Сухомлинский под трудовым воспитанием понимал гармонию понятий «надо», «трудно» и «прекрасно». Он полагал, что воспитания нет и быть не может без труда и вне труда [2].

А.С. Макаренко писал, что труд сам по себе не является воспитательным средством. Воспитательным средством труд может быть только в том случае, если он организован с определённой целью, определённым образом и является частью воспитательного процесса [3].

В методике обучения естествознанию одним из первых поднял вопрос об уважительном отношении к труду в первой половине XIX в. автор учебника по ботанике для кадетских заведений В.И. Даль [4].

Известные методисты-биологи И.Д. Зверев и А.Н. Мягкова утверждали, что «необходимо так воспитывать учащихся, чтобы труд стал для них первейшей потребностью, жизненной необходимостью» [5, с. 102].

Теоретические основы и практические подходы к трудовому воспитания и профессиональной ориентации учащихся в процессе обучения биологии и экологии раскрыты в работах учёных-методистов Н.Д. Андреевой, В.С. Анисимовой, Н.Г. Бобровой, Е.Т. Бровкиной, И.Д. Зверева, Н.В. Малиновской, А.Н. Мягковой и др. [6-14].

В публикациях последних лет по проблеме трудового воспитания и профориентации учащихся затрагиваются вопросы изменения уроков биологии и экологии с целью усиления степени профессионального самоопределения школьников [15]; психологического сопровождения профессиональной ориентации учащихся в старшей школе [16]; формирования у школьников первоначальных профессиональных намерений и интересов через элективные курсы [17] и летнюю научно-исследовательскую школу [18]; профориентации старшеклассников в условиях быстро меняющегося рынка труда [19] и др.
Из изложенного выше видно, что со временем происходит смещение акцента с трудового воспитания учащихся как такового в сторону профессиональной ориентации школьников. Этот акцент в настоящее время усиливается за счёт перехода старшей школы на новый стандарт, который ориентирован на подготовку выпускника к осознанному выбору профессии, понимающего значение профессиональной деятельности для человека и общества [20].

Целью настоящей статьи стала разработка методических аспектов трудового воспитания и профессиональной ориентации в биологическом и экологическом образовании школьников с учётом требований ФГОС СОО.

Работа выполнена на основе изучения литературы и других источников с использованием метода теоретического анализа и синтеза [21].

К настоящему времени существует много профессий и специальностей требующих биологические знания и умения, основы которых ученикам могут быть заложены на уроках биологии и экологии, экскурсиях, во внеклассной, внеурочной и внешкольной работе, а также в процессе общественно-полезного труда.

Отношение человека к труду, активность его трудовой деятельности, творческий подход к ней зависит от верного выбора профессии вообще и специальности в частности. В связи с этим правильная подготовка учащихся к будущей трудовой деятельности имеет первостепенное значение в воспитании школьников [9]. В процессе профподготовки учащихся главная задача учителя - вызвать интерес учеников к тем или иным профессиям, связанным с биологией и экологией.

Одной из основ трудового воспитания является профориентация учащихся. Она является задачей первостепенной важности и составляет принципиальное отличие углублённого уровня изучения биологии в старших классах от базового [22]. Профессиональная ориентация рассматривается как условие всестороннего и гармоничного развития личности; осуществляется в единстве обучения биологии и экологии с основными направлениями духовнонравственного развития, воспитания и социализации учащихся.

Профессиональная ориентация предполагает целенаправленную деятельность по формированию у школьников внутренней потребности и готовности к сознательному выбору профессии. В системе профориентационной работы выделяют несколько компонентов:

- профессиональное просвещение;

- профессиональное воспитание;

- профессиональную консультацию;

- профессиональную адаптацию [7].

Профессиональное просвещение вооружает школьников знаниями о профессиях в области биологии и экологии, условиях их выбора, воспитывает у них положительное отношение к труду, формирует профессиональные интересы и предпочтения. Оно вклю- 
чает в себя профинформацию, профпропаганду и профагитацию. Их цель - сообщение школьникам сведений о биологических и экологических профессиях, информирование их о способах и условиях овладения ими, знакомство с редкими для региона и потому востребованными профессиями.

Профессиональное просвещение способствует развитию интересов и склонностей учащихся в области биологии и экологии, которые не могут не оказывать влияние на выбор будущей профессии, способствует их интеллектуальному развитию.

Профессиональное воспитание школьников один из главных компонентов системы профориентации. Под профессиональным воспитанием понимают воспитание у учащихся профессионально важных качеств личности: коммуникабельности, профессионального долга и чести, ответственности, профессиональной этики и пр. Профессиональное воспитание в школе организуется на всех уровнях управления - администрацией школы, школьным советом, классным руководителем, учителями-предметниками, в том числе биологии и экологии.

Учитель знакомит учащихся с профессиями, связанными с биологией и экологией; изучает и развивает интересы, склонности и способности каждого ученика; включает профориентационную тематику в оформление учебного кабинета; обеспечивает регулярную демонстрацию видеофильмов, отражающих применение достижений биологических наук и экологии в производстве.

С целью профессиональной ориентации учащихся учитель может воспользоваться всем арсеналом методов обучения биологии и экологии. Их выбор зависит от цели, образовательных задач, содержания учебного материала, особенностей учащихся, а также уровня профориентационной готовности школьников [16].

Метод рассказ используют при изложении общей характеристики профессии в области биологии или экологии, её значении, требований профессии к личности, условий труда, необходимых знаний, требуемых умений и навыков, а также мест получения.

Метод объяснение применяют для сообщения сути той или иной профессии, биологической или экологической направленности, её особенностей; разъяснения новых понятий, трудовых приёмов и операций.

Применение рассказа и объяснения должно быть чётким, последовательным, лаконичным и эмоциональным, а содержание - достоверным, соответствовать действительности, отражать современное состояния развития биологических наук и экологии, производства, содержание труда представителей этих профессий.

Наиболее распространённым словесным методом профориентационной работы с учащимися считается беседа. Она строится на заранее подготовленных учителем и учащимися вопросах о профессиях, связанных с биологией и экологией. Беседа должна быть связана с изучаемым материалом. Она может сопровождаться высказываниями и отрывками из биографий известных людей, которые прошли большой и яркий жизненный путь в одной из биологических или экологических профессий.
Наряду со словесными методами необходимо использовать наглядные методы. Для этих целей хорошо подходит демонстрация:

- натуральных объектов, выполненных в том или ином биотехнологическом процессе;

- изобразительных пособий;

- видеофильмов и их фрагментов с последующим обсуждением;

- приёмов деятельности во время выполнения лабораторных и практических работ.

По мнению Н.Г. Бобровой, использование практических методов (наблюдение, эксперимент, распознавание и определение объектов) в профориентационной работе учащихся способствует не только лучшему усвоению биологического и экологического материала, но и выработке определенных профессиональных умений [9].

К основным формам профориентационной работы в процессе обучения биологии можно отнести:

- урок, в том числе профинформационные уроки;

- экскурсии на биологические и экологические предприятия, а также в профессиональные учебные заведения медико-биологического и сельскохозяйственного направлений подготовки;

- посещение производственных выставок (например, сельскохозяйственных) и дней открытых дверей в учебных заведениях среднего профессионального и высшего образования;

- встречи с представителями профессий в области биологии и экологии;

- участие в биологических и экологических олимпиадах и конкурсах;

- посещение факультативов, элективных курсов и курсов по выбору медико-биологической, экологической, природоохранной и сельскохозяйственной направленности;

- внеклассные биологические и экологические мероприятия, вечера;

- общественно-полезный труд и внешкольная работа по биологии и экологии.

Ниже остановимся на некоторых из них. Наибольшее значение в профориентации играют вводные уроки по изучению соответствующих тем, разделов и школьных курсов биологии и экологии в целом. На этих уроках можно ознакомить учащихся не только с тем, что предстоит изучать им в дальнейшем, но и со значением различных профессий и специальностей для развития биологии и экологии как наук, развитием тех или иных отраслей производства, связанных с изучаемыми предметами.

Большую роль в работе по профориентации играют профинформационные уроки в 9-11 классах. На них нередко приглашают специалистов-биологов, экологов, врачей, представителей сельскохозяйственных профессий, которые рассказывают о своих профессиях от первого лица и отвечают на вопросы учеников [8].

Одной из важных форм по ознакомлению учащихся с профессиями, связанными с биологией и экологией, является экскурсия. В школьном курсе биологии предусмотрены экскурсии на производство при изучении тем «Основы генетики и селекции», «Искусственный отбор». При изучении растений и грибов экскурсии можно провести в оранжерею, теплицу, завод по выращиванию шампиньонов. На них 
ученики узнают о способах выращивания растений и грибов, об агротехнике их возделывания, знакомятся со спецификой работы растениеводов и технологов по выращиванию грибов. При изучении животных экскурсии можно организовать на животноводческие фермы, где школьники узнают о работе животноводов и различных их специальностях [11].

В школьном курсе экологии возможно проведение экскурсий на очистные сооружения, мусороперерабатывающий завод, экологическую лабораторию и т.п.

В рамках внеурочной деятельности учащимся старших классов можно предложить посетить элективный курс «В мире биологических и экологических профессий» [17].

В выборе будущей профессии учащимся могут помочь внеклассные мероприятия, посвященные биологическим и экологическим профессиям, занятия в работе биоэкологического кружка, индивидуальная исследовательская деятельность учащихся по биологии и экологии.

Поскольку профориентация немыслима без трудовой деятельности самих школьников, то не меньшее значение имеет общественно-полезный труд, в процессе которого учащиеся знакомятся с основными видами трудовой деятельности биологической, экологической и природоохранной направленности. Он может осуществляться в кабинете биологии, в уголке живой природы, на учебно-опытном участке, в рамках летней производственной практики.

Трудовое воспитание и профориентация учащихся возможны также и во внешкольной работе в составе школьных лесных бригад или бригад по озеленению территории [23], уборке мусора; «зелёных» и «голубых» патрулей, дружины по охране природы.

Профессиональная консультаиия помогает учащимся в профессиональном самоопределении. Она предполагает информирование школьников о биологических и экологических профессиях. Профконсультация включает проведение мероприятий, которые направлены на изучение профессионально значимых качеств личности и позволят ученикам сделать осознанный выбор своей будущей профессии.

Профессиональная консультация может быть проведена в форме индивидуальных или групповых бесед и занятий.

Профессиональная адаптация связана с овладением учащимися необходимыми для будущей профессии знаниями и практическими умениями. Существует прямая зависимость между уровнем биоэкологических знаний и умений и скоростью адаптации человека к профессиональному обучению и трудовой деятельности [7].

Таким образом, трудовое воспитание и профессиональная ориентация учащихся в процессе обучения биологии и экологии представляет собой целостную систему, состоящую из взаимосвязанных и дополняющих друг друга компонентов, объединённых общностью цели и единством управления.

\section{Список литературы:}

1. Ушинский К.Д. Избранные педагогические сочинения. В 2 т. М.: Учпедгиз, 1953-1954.

2. Сухомлинский В.А. Избранные педагогические сочинения. В 3 т. М.: Педагогика, 1979-1981.
3. Макаренко А.С. Педагогические сочинения. М.: Изд-во АПН РСФСР, 1948. 303 с.

4. Пономарева И.Н., Роговая О.Г., Соломин В.П. Методика обучения биологии: учебник для студ. учреждений высш. проф. образования / под ред. И.Н. Пономаревой. М.: Издательский центр «Академия», 2012. $368 \mathrm{c.}$

5. Зверев И.Д., Мягкова А.Н. Общая методика преподавания биологии: пособие для учителя. М.: Просвещение, 1985. 191 с.

6. Андреева Н.Д., Малиновская Н.В. Профессиональная ориентация учащихся // Биология в школе. 2003. № 1. С. 37-43.

7. Андреева Н.Д., Соломин В.П., Васильева Т.В. Теория и методика обучения экологии: учебник для студ. высш. учеб. заведений. М.: Издательский центр «Академия», 2009. 208 с.

8. Анисимова В.С., Бровкина Е.Т., Мягкова А.Н. Политехническое образование и профориентация в преподавании биологии: метод. пособие для учителей. М.: Просвещение, 1982. 192 с.

9. Боброва Н.Г. Формирование профессиональных предпочтений школьников в процессе обучения биологии // Современное естественнонаучное образование: достижения и инновации: IV всерос. (с междунар. уч.) науч.-метод. конф. Красноярск, 14-15 ноября 2013 г. Красноярск: КГПУ им. В.П. Астафьева, 2013. С. 29-33.

10. Верзилин Н.М., Корсунская В.М. Общая методика преподавания биологии: учеб. для студ. биол. фак. пед. ин-тов. М.: Просвещение, 1976. 384 с.

11. Захаров Н.Н., Симоненко В.Д. Профессиональная ориентация школьников. М.: Просвещение, 1989. $192 \mathrm{c}$

12. Ионина Н.Г., Войткевич Н.Н. О профессиональном самоопределении старшеклассников // Биология в школе. 2010. № 3. С. 47-52.

13. Малиновская Н.В. Профессиональная ориентация при обучении биологии в старших $(9,10,11)$ классах: автореф. дис. ... канд. пед. наук. СПб., 1999. $18 \mathrm{c}$.

14. Якунчев М.А., Маркинов И.Ф., Ручин А.Б. Методика преподавания биологии: учебник для студ. учреждений высш. образования / под ред. М.А. Якунчева. М.: Издательский центр «Академия», 2014. $336 \mathrm{c}$.

15. Ионина Н.Г. Профессиональное самоопределение школьников через трансформацию урока // Биология в школе. 2018. № 4. С. 67-72.

16. Мельникова Н.А. Психологическое сопровождение профессиональной ориентации учащихся в старшей школе. Профессии без границ: мат-лы междунар. науч.-практ. конф., г. Новочебоксарск, 2728 февраля 2014 г. Новочебоксарск: Изд-во «Полиграфика», 2014. С. 195-204.

17. Миназева Л.Б. Элективный курс «В мире биологических профессий» как средство формирования у школьников первоначальных профессиональных намерений и интересов // Студенческий вестник: научный журнал. 2019. № 20 (70). Ч. 1. С. 46-49.

18. Минькова Н.О., Королькова Е.О. Летняя научно-исследовательская школа как форма профориентационной работы с учащимися // Биология в школе. 2014. № 5. C. 64-68. 
19. Николенко Т.Г. Профориентация старшеклассников в условиях быстро меняющегося рынка труда // Биология в школе. 2018. № 6. С. 28-32.

20. Федеральный государственный образовательный стандарт среднего (полного) общего образования (утвержден приказом Минобрнауки России от 17 мая 2012 г. № 413) [Электронный ресурс] // Федеральные государственные образовательные стандарты. https://fgos.ru.

21. Загвязинский В.И., Атаханов Р. Методология и методы психолого-педагогического исследования: учеб. пособие для студ. высш. пед. учеб. заведений. М.: Издательский центр «Академия», 2003. 288 с.

22. Примерная основная образовательная программа среднего общего образования. Одобрена решением федерального учебно-методического объединения по общему образованию (протокол от 28 июня 2016 г. № 2/16-3) [Электронный ресурс] // Реестр примерных основных общеобразовательных программ. Министерство образования и науки Российской Федерации. http://fgosreestr.ru.

23. Зеленый патруль: книга для учителя. М.: Просвещение, 1984.128 с.

\title{
LABOR EDUCATION AND PROFESSIONAL ORIENTATION IN BIOLOGICAL AND ECOLOGICAL EDUCATION OF PUPILS
}

\author{
Semenov Aleksandr Alekseevich, candidate of biological sciences, associate professor, \\ head of Chair of Biology, Ecology and Methods of Teaching \\ Samara State University of Social Sciences and Education (Samara, Russian Federation)
}

\begin{abstract}
The attitude of a person to work, the activity of his work, creative approach to it depends on the right choice of profession, in general, and specialty in particular. In this regard, the correct training of pupils for future employment is of paramount importance in the education of schoolchildren. One of the foundations of labor education is vocational guidance of pupils. It is considered as a condition of all-round and harmonious development of the personality; the unity of teaching Biology and Ecology with the main directions of spiritual and moral development, education and socialization of pupils. Professional orientation involves purposeful activities to form pupil's internal needs and readiness for conscious choice of profession and consists of several components: professional education; professional upbringing; professional advice; professional adaptation. Professional education equips pupils with knowledge about professions in the field of Biology and Ecology, conditions of their choice, educates them a positive attitude to work, forms professional preferences. Professional upbringing is the education of pupil's professionally important qualities of personality: communication skills, professional duty and honor, responsibility, professional ethics and others. The teacher introduces pupils to the professions related to Biology and Ecology; studies and develops the interests, aptitudes and abilities of each pupil; includes career guidance topics in the design of the classroom; provides regular demonstration of videos reflecting the application of the achievements of biological science in production. Professional advice is designed to provide pupils with necessary assistance in professional selfdetermination. It involves informing pupils about biological and environmental professions. Professional adaptation is associated with the acquisition of necessary knowledge and practical skills for pupil's future profession. There is a direct correlation between the level of subject knowledge and skills and the speed of adaptation of a person to professional training and work. Thus, labor education and professional orientation of pupils in the process of teaching Biology and Ecology is a holistic system consisting of interrelated and complementary components, united by a common goal and unity of management.

Keywords: education; training; spiritual and moral development; work; profession; professional orientation; Biology; Ecology; pupils; school; labor education; methods of Biology teaching; methods of Ecology teaching; biological education; environmental education; secondary general education.
\end{abstract}

\section{РАЗВИТИЕ ИНОЯЗЫЧНОЙ СТРАТЕГИЧЕСКОЙ КОМПЕТЕНЦИИ У СТУДЕНТОВ НЕЯЗЫКОВЫХ СПЕЦИАЛЬНОСТЕЙ}

Татарина Татьяна Михайловна, кандидат педагогических наук, доцент кафедры иностранных языков гуманитарных направлений Петрозаводский государственный университет (г. Петрозаводск, Российская Федерация)

Аннотация. Современный выпускник российского вуза должен демонстрировать не только широкий спектр компетенций в рамках выбранного профиля, но и владеть большим набором универсальных или ключевых компетенций. Одной из универсальных компетенций выпускника вуза по каждому направлению подготовки бакалавриата является иноязычная коммуникативная компетентность. В рамках данной статьи автор рассматривает особенности устной коммуникации студентов неязыкового факультета, а также взгляды специалистов на трудности, препятствующие общению. Приведены данные психолого-педагогического исследования (опросник Кеттелла, языковое тестирование, наблюдение преподавателя) первокурсников экономи- 